\title{
A Review of Scientific Topics and Literature in Abdominal Radiology in Germany - Part 1: Gastrointestinal Tract
}

\section{Aktuelle Schwerpunkte und Literatur der Abdominalradiologie im deutschsprachigen Raum - Teil 1: Gastrointestinaltrakt}

Authors

Affiliations
A. G. Schreyer ${ }^{1}$, J. Wessling ${ }^{2}$, S. Kinner ${ }^{3}$, M. S. Juchems ${ }^{4}$, K. Holzapfel ${ }^{5}$, T. C. Lauenstein ${ }^{3}$, P. Konietzke ${ }^{6}$, L. Grenacher ${ }^{7}$

Affiliation addresses are listed at the end of the article.

Key words
abdomen
stomach
small bowel
colonoscopy
inflammation

received 17.2.2015 accepted $\quad 6.7 .2015$

Bibliography

DOI http://dx.doi.org/

10.1055/s-0041-104892

Published online: 2.9 .2015

Fortschr Röntgenstr 2016; 188:

134-145 @ Georg Thieme

Verlag KG Stuttgart · New York . ISSN 1438-9029

\section{Correspondence}

Prof. Andreas G. Schreyer

Institut für Röntgendiagnostik, Universitätsklinikum

Regensburg

Franz-Josef-Strauß-Allee 11

93051 Regensburg

Germany

Tel.: ++ 49/9 41/9447401

Fax: ++ 49/941/9447402

andreas.schreyer@klinik.uni-

regensburg.de

\section{Abstract}

The working group for abdominal and gastrointestinal diagnosis is a group of the German Radiological Society (DRG) focusing clinically and scientifically on the diagnosis and treatment of the gastrointestinal tract with all parenchymatous abdominal organs. In addition to the clinical and scientific further development of abdominal radiology, the education of radiologists within this core discipline of radiology is one of the major aims. In this article we give an up-to-date literature review of scientific radiological topics especially covered by German radiologists. This manuscript focuses on the most recent literature on the diagnosis of the stomach, small bowel, colon and rectum. The review with a focus on the most recent studies published by German radiologists concludes with a synopsis of mesenterial bleeding and ischemia followed by a critical appraisal of the current literature on conventional abdominal radiography.

Key Points:

- Based on recent literature and guidelines there is a change of paradigms regarding the diagnosis of esophagus and gastric cancer towards CT, which is considered equally to endosonography.

- For small bowel imaging in Crohn's disease ultrasound as well as MRI with a new focus on DWI are the most important imaging modalities scientifically.

- For colonic diagnosis virtual colonoscopy has replaced the conventional radiological methods. For staging of rectal carcinoma as well as for therapeutic stratification a high resolution MRI of the pelvis is of paramount interest.
- Multislice CT is considered the most important modality to assess mesenteric ischemia or bleeding.

Citation Format:

- Schreyer AG, Wessling J, Kinner S etal. A Review of Scientific Topics and Literature in Abdominal Radiology in Germany - Part 1: Gastrointestinal Tract. Fortschr Röntgenstr 2016; 188: 134-145

\section{Zusammenfassung}

$\nabla$

Die AG Abdominal- und Gastrointestinaldiagnostik ist die Arbeitsgemeinschaft der Deutschen Röntgengesellschaft (DRG), die sich klinisch und wissenschaftlich auf Diagnostik und Therapie des Gastrointestinaltraktes mit allen parenchymatösen Abdominalorganen fokussiert. Neben der klinischen und wissenschaftlichen Weiterentwicklung der abdominellen Radiologie ist die Weiterbildung aller Radiologen in diesem Kernfach ein Hauptziel der Arbeitsgruppe. Im vorliegenden Übersichtsartikel wird eine aktuelle Übersicht forschungsrelevanter Themengebiete vor allem der deutschsprachigen Radiologie, gegeben. Der Fokus dieses Artikels richtet sich dabei auf die Diagnostik des Magens, Dünndarms und Dickdarms mit Rektum. Abgeschlossen wird der Übersichtsartikel der aktuellen Literatur mit Betonung der radiologischen Entwicklungen im deutschsprachigen Raum mit einer Synopsis der mesenterialen Blutung und Ischämie gefolgt von einer kritischen Würdigung aktueller Literatur zum konventionellen abdominellen Röntgen.

\section{Introduction}

The working group for abdominal and gastrointestinal diagnosis (www.ag-gastro.drg.de) is a group of the German Radiological Society 
(DRG) that focuses on one of the main core areas of radiology. The working group is a representative of German abdominal radiology and a comprehensive platform for interested researchers and clinicians with a focus on radiological abdominal diagnosis and therapy.

In addition to active work on guidelines that is impressively supported by all members of the working group and the board in recent years and currently, the working group would also like to promote and support advanced training in abdominal radiology in Germany.

For this reason we tried to make the expertise of our active members regarding research and clinical practice in abdominal radiology available to the members of the German Radiological Society. Therefore, a current overview of the literature with a focus on the developments and trends of gastrointestinal and abdominal radiology in Germany in recent years was created in the following publication. To improve clarity, we tried to structure the topic of gastrointestinal and abdominal diagnosis with respect to content and topography. Therefore, we will focus on hollow gastrointestinal organs in the first part of this overview. The parenchymal abdominal organs will be discussed separately in another publication. Our intention was to represent and discuss the issues and radiological problems that have been increasingly researched in recent years in the individual organ and hollow organ regions and review the relevant international literature. The important German publications subjectively selected by the authors are then presented and discussed. The paper is structured anatomically from cranial to caudal. In particular, the diagnosis of the esophagus and stomach based on current guidelines is discussed. This is followed by an overview of small intestine diagnosis with subclassification of the issues and studies according to the individual working groups. In colorectal diagnosis, in addition to CT and MRI colonoscopy, primarily MRI-based evaluation of rectal cancer is discussed. As in the case of the small intestine, this topic is also analyzed here in the context of the updated new German guidelines. In addition to the hollow gastrointestinal organs, mesenteric bleeding and ischemia are discussed. The overview concludes with additional varia regarding gastrointestinal radiology with a focus on graft versus host disease and the current assessment of conventional radiography in the context of modern cross-sectional imaging of the abdomen.

The individual chapters regarding the particular organ and intestinal regions were written by the experts and the board of the working group for abdominal and gastrointestinal diagnosis and were edited, supplemented, and compiled in consensus under the supervision of the chairmen of the working group.

\section{Esophagus|stomach}

In esophageal and gastric cancer, the TNM stage is prognosis-relevant which is why exact pretherapeutic cross-sectional imaging prior to the start of therapy is obligatory [ 1 4]. In recent years the advances in cross-sectional imaging as a result of further developments in scanner technology and protocol optimizations have been studied so systematically that the previous diagnostic algorithms were fundamentally revised during the creation of the $\mathrm{S} 3$ guidelines re- garding esophageal and gastric cancer incl. tumors of the esophageal gastric junction [5]. The role of radiology has changed significantly despite the unchanged use of esophagogastroscopy with biopsy as the gold standard for the detection of neoplasias of the upper gastrointestinal tract [6].

\section{Barium swallow \\ $\nabla$}

Barium swallow is no longer used in the staging of esophageal cancer $[7,8]$ or gastric cancer and is now considered obsolete in the guidelines. It is only still useful in the clarification of tracheoesophageal fistulas or a higher grade lumen obstruction [9-12] with the use of a water-soluble contrast agent.

\section{Endoscopic ultrasound (EUS) \\ $\nabla$}

Endoscopic ultrasound (EUS) was an integral part of the staging of esophageal cancer in patients with a curative treatment intention [13-15]. Contrast-enhanced endoscopic ultrasound (CE-EUS) and ultrasound elastography are new methods for which significant data is not yet available. The previous use of EUS in local T-staging is significantly weakened by the available data regarding multidetector CT. Therefore, EUS is now only to be performed as a complementary method to $\mathrm{CT}$ in the staging of gastric cancer.

\section{B-mode ultrasound \\ $\nabla$}

In esophageal cancer and adenocarcinoma of the gastroesophageal junction, B-mode ultrasound of the neck can be used instead of CT of the neck to rule out cervical lymph node metastases. In gastric cancer, it is only indicated in the case of clinical suspicion. It is equivalent or slightly superior to CT [7, 8, 15 - 17]. For the histological verification of cervical lymph nodes, fine-needle aspiration (FNA) can be performed with the help of ultrasound [17-20]. As a simple and readily available method, B-mode ultrasound of the liver should continue to be liberally used as the first measure to rule out liver metastases [21-23], in particular to clarify the decision for curative or palliative treatment. Contrastenhanced ultrasound (CEUS) is comparable with CT and MRI for the detection of liver metastases [23-28]. There are currently no high quality studies regarding laparoscopic or intraoperative ultrasound of the liver.

\section{Computed tomography (CT)}

In the case of esophageal cancer, the esophagus should be fully visualized in patients with a curative treatment approach while $\mathrm{CT}$ of the thorax and abdomen seems sufficient in the case of gastric cancer. In both cases, i.v. administration of an iodine-containing contrast agent is required [29]. The hydro-technique with wall distension [30], primarily using a negative oral contrast agent, ideally $1-1.51$ water under spasmolysis, can be used for optimization ( $\bullet$ Fig. 1). This improves the visualization of the esoph- 

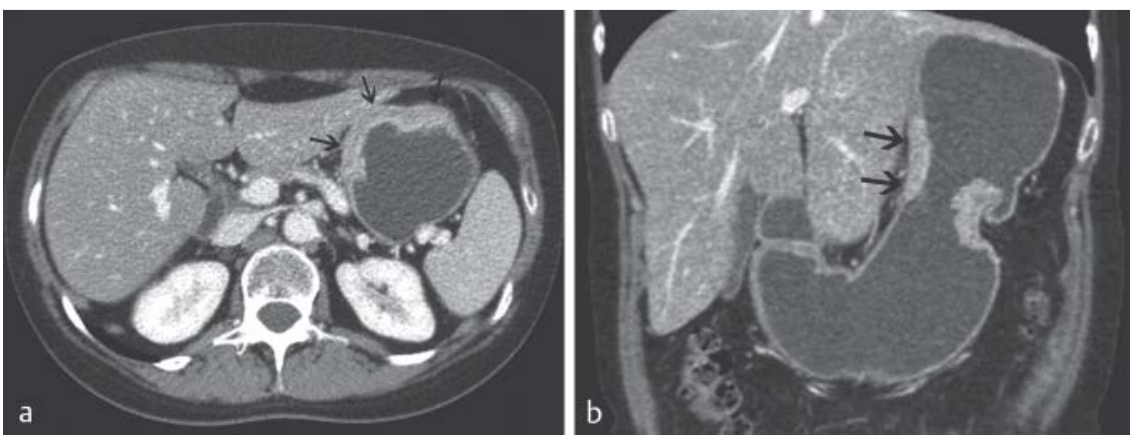

Fig. 1 Axial a and coronal $\mathbf{b}$ hydro $\mathrm{CT}$ of the stomach: (black arrows) tumor-bearing gastric wall at the small curvature $\mathbf{a}$, and circular tumor growth in the coronal image $\mathbf{b}$ detectable with tumor-bearing gastric wall on the small curvature side (black arrows) and on the large curvature side.

ageal wall or the gastric wall and increases the diagnostic significance regarding local findings and infiltration of adjacent organs. In the case of esophageal cancer, CT is limited with regard to T-staging in the early stages but can be correctly performed in $76 \%$ of cases [31]. Correct T-staging of gastric cancer is achieved in $77-89 \%$ of cases [32]. CT and EUS are now comparable in the evaluation of serosal infiltration. The evaluation of the N-stage continues to be problematic as in almost all other diagnostic methods. It was shown in a current meta-analysis that a reliable statement cannot be made with EUS, CT, or MRI for the evaluation of lymph node metastases in gastric carcinoma [33]. However, EUS seems to be more sensitive than CT in the staging of locoregional lymph nodes in esophageal cancer [34]. A combination of PET-CT, MDCT, and EUS achieves the highest accuracy for the determination of lymph node status in esophageal cancer [35].

\section{Magnetic resonance imaging (MRI) \\ $\nabla$}

If CT cannot be performed, MRI can be used as an alternative method. There are currently no standardized protocol recommendations. A layer thickness analogous to CT, a field strength of at least 1.5 Tesla, and standard weighting with contrast enhancement are reasonable. There is also no clear recommendation for the use of specific MRI contrast agents when searching for metastases. Their benefit is the subject of current studies [33, 36, 37]. TNM staging of esophageal cancer via MRI is comparable with CT [38], in particular in tumors of the gastroesophageal junction [36], but is less exact for pulmonary lesions [39]. MRI is not superior to CT in any region [40]. In the case of higher T-categories, hydro-MRI of the stomach achieves similar results to CT in T-staging [33, 41]. Current developments in MRI are to provide more precise visualization of the esophageal wall and thus better visualization of the depth of infiltration [10]. The diagnostic value of MRI for T-staging can be expected to increase further. However, the available number of high-quality studies is currently still too low for clear conclusions. Moreover, functional MRI as so-called diffusion MRI [42] can provide valuable information, e.g. in the evaluation of individualized treatment concepts, beyond pure morphology.

\section{Positron emission tomography (PET-CT)} $\nabla$

PET-CT is not routinely recommended for the staging of esophageal or gastric cancer in the updated S3 guidelines.
In a curative treatment option for advanced esophageal cancer ( $\mathrm{N}+$ and $\mathrm{T} 2-4)$, PET/CT can be useful for M-staging. There is a significant discrepancy regarding the evaluation of the diagnostic value of PET/CT in Germany and the USA. Therefore, PET/CT is compensated in the USA based on the relevance for patients for $\mathrm{M}$-staging. According to experts, unnecessary operations can be avoided by detecting previously occult distant metastases. However, systematic studies on the topic are still lacking. Numerous studies, albeit with small case numbers, show the diagnostic value of PET/CT for the detection of distant lymph node metastases: $17 / 24$ with PET/CT vs. 7/24 with CT/EUS [43] and thus a change in the treatment management of patients of up to $34 \%[44]$.

\section{Small intestine and chronic inflammatory bowel diseases \\ $\nabla$}

The main focus of radiological imaging of the small intestine is the diagnosis of rare tumors of the small intestine as well as the diagnosis of inflammatory changes in chronic inflammatory bowel diseases. The majority of scientific publications on the topic of small intestine diagnosis regarding imaging modalities are based on the recommendations of the updated German S3 guidelines for Crohn's disease [45, 46]. In principle, high-resolution ultrasound of the small intestine and MRI examination of the small intestine such as enterography or enteroclysis are postulated as the primary comprehensive small intestine visualization methods. Therefore, many publications and German working groups address the selection of the optimal radiological modality for detecting inflammation in chronic inflammatory bowel diseases. Other important issues in the international literature in recent years include the possible differentiation of inflammatory and fibrous changes in affected intestinal segments.

In the Regensburg working group of Schreyer, magnetic resonance enterography (MRE) with and without biphasic contrast enema was compared with conventional ileocolonoscopy in patients with Crohn's disease [47]. Therefore, improved detection of inflammatory changes in the terminal ileum is postulated in examinations performed with a rectal water enema. In the same working group, diagnosis with high-resolution ultrasound and MRE in patients with chronic inflammatory bowel disease was retrospectively compared [48]. It was shown that ultrasound can miss clinically relevant changes since some anatomical regions are difficult to visualize. However, in a study using contrast-enhanced ultrasound, a significant correlation with his- 

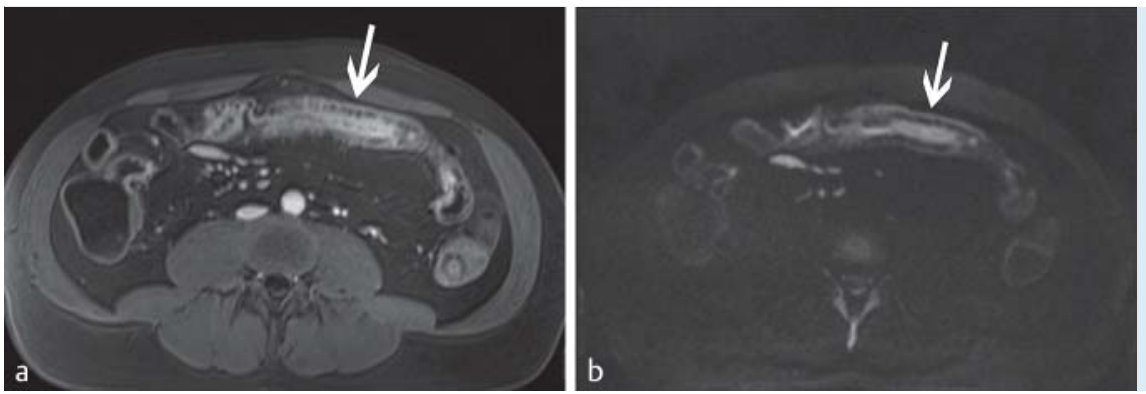

Fig. 2 Patient with active inflammatory changes of the small intestine in Crohn's disease: The a axial fat-saturated $3 \mathrm{D}$ gradient echo sequence after intravenous contrast application shows three-layer intestinal wall thickening with increased contrast enhancement in terms of acute inflammation. The same information is provided in the $\mathbf{b}$ axial native diffusion-weighted sequence/DWI $(b=800)$.

topathological changes in patients with Crohn's disease regarding the quantitative evaluation of intestinal wall vascularization was found [49]. There was a strong correlation of contrast-enhanced ultrasound regarding clinical inflammation markers [50]. In patients with known chronic inflammatory bowel disease and acute abdominal pain, the same working group additionally showed that regular emergency CT for intestinal wall evaluation is sufficient and no additional MRE studies are necessary since an advanced finding is often present in these patients [51]. In a further study of the Regensburg group, it was able to be shown in patients undergoing bowel resection that MRE is an excellent imaging modality to correctly evaluate the Montreal classification of disease behavior [52]. The extent to which MRE can be used as an independent objective imaging method in the diagnosis and treatment of Crohn's disease was evaluated in an additional study [53]. MRE showed high interobserver agreement in the diagnosis of inflammatory activity while bowel distension and lymphadenopathy had only moderate interobserver agreement, which however had only a minimal effect on the diagnostic significance of the method in the clinical routine. The Münster working group of Lenze et al. compared MRE with 18FFDG PET/CT and ultrasound with endoscopy and histopathology in the detection of active and fibromatous changes of Crohn's disease [54]. The detection rate of strictures was not significantly different but neither PET/CT nor MRE nor ultrasound could differentiate inflammatory from fibrotic strictures. Moreover, the combination of MRE and ultrasound as well as PET/CT and ultrasound had a $100 \%$ detection rate of strictures requiring surgical or endoscopic dilatation therapy. Holtmann et al. also analyzed 18F-FDG PET in the diagnosis of Crohn's disease [55] and found that FDG-PET detected inflammation of the mucosa in Crohn's disease with high sensitivity and specificity and proved the value of the evaluation of inflammatory activity with Gallium-DOTATOC-PET/CT for the diagnosis of neuroendocrine tumors in the small intestine [56].

Additional groups addressed the application of new abdominal MR sequences: Kinner et al. were able to show in the Essen working group that diffusion-weighted imaging (DWI) in bowel diagnosis with MRI ( $\bullet$ Fig. 2 ) increases diagnostic reliability [57]. The same working group published that DWI showed inflammatory lesions of the bowel with higher reliability in children and adolescents with chronic inflammatory bowel disease than contrast-enhanced T1weighted sequences alone [58]. In addition, there is a study by Neubauer et al. [59] that also concluded that contrast administration when using DWI is no longer necessary.
Multiple German working groups studied intestinal motility and its correlation in chronic inflammatory bowel disease. In 2013 Bickelhaupt et al. showed the first options for the automatic measurement of small bowel contractions [60] and demonstrated that automatic measurement is better than manual [61]. Moreover, the same working group was able to show that small bowel motility correlates with the histopathology of the terminal ileum [62] as well as with inflammatory markers [63] and can differentiate active from chronic inflammatory processes [64]. In addition, the group analyzed prelesional and intralesional motility and found that the extent of the inflammation did not correlate with restricted movement [65]. Animal studies of this group also showed the value of the imaging of intestinal movement [66]. Hahnemann et al. evaluated an automatic color-coded algorithm for evaluating intestinal motility [67] and were able to show an increased detection rate of inflammatory lesions using this technique [68].

Additional studies addressing MRE at 3 Tesla in the diagnosis of (neo-)ileitis terminalis [69] have been published in the last three years. The authors again highlight the value of MRE at 3 Tesla for the evaluation of foci of inflammation in the ileum in chronic inflammatory bowel diseases. An animal study with gadofluorine $\mathrm{M}$ showed a higher correlation between intestinal wall enhancement and histopathological grading than Gd-DTPA-enhanced imaging [70].

\section{Colon and rectum \\ $\nabla$ \\ Virtual colonoscopy}

For virtual colonoscopy the current S3 guidelines [71] provide consensus-based recommendations in the case of incomplete colonoscopy due to a stenosed tumor (level of evidence 4 , recommendation level 0 , coordination in plenum: strong consensus) and as a result of other causes (e.g. adhesions, level of evidence 4, recommendation level B). Virtual colonoscopy has almost completely replaced double contrast examination of the colon in the clinical routine. The most important indications include incomplete or not implementable colonoscopy and patients under anticoagulation therapy. The European Society of Gastrointestinal Endoscopy (ESGE) and the European Society of Gastrointestinal and Abdominal Radiology (ESGAR) recently created joint guidelines for determining the indication for virtual colonoscopy [72]. The guidelines view virtual colonoscopy as an acceptable and equally sensitive alternative method in the case of suspicion of colorectal cancer and not implementable conventional colonoscopy (strong recommendation, high quality evidence). The role of virtual 
colonoscopy in colorectal preventive care remains controversial. Virtual colonoscopy is not taken into consideration for colorectal preventive care in the current S3 guidelines [82]. Virtual colonoscopy is also not recommended as the primary method in colorectal preventative care in Europe [72]. However, there is agreement that virtual colonoscopy can be recommended to the patient on an individual basis after the provision of sufficient clarification and information (weak recommendation, moderate quality evidence). Based on the increasing amount of scientifically sound data, multiple professional associations including the American Cancer Society and the American College of Radiology have argued for the use of virtual colonoscopy as part of preventive care. However, in March 2009 Medicare Service took an adverse stance to the financing of virtual colonoscopy in colorectal preventive care. Medicare's arguments were mainly based on three points of criticism: A) Risks of radiation exposure, B) Transferability of current data to persons older than 65 years and C) The unclear data regarding the relevance of extracolonic findings, i.e., possibly clinically relevant findings outside the colon. These points have been systematically and scientifically addressed: Regarding A): With respect to radiation exposure, an effective dose $<3 \mathrm{mSv}$ can be assumed under screening regulations. According to Berrington de Gonzáles [73] from the U.S. National Cancer Institute, the risk/benefit ratio is $1: 24$ to $1: 35$. Accordingly, the cancer risk in a patient who is over 30 years old and receives a virtual colonoscopy every 5 years is significantly less than $1 \%$ and is thus lower than the lifetime risk of getting colon cancer without preventive care of approximately $6 \%$. Regarding B): Data regarding the transferability to older patients were published as part of subgroup analyses of the ACRIN 6664Trial and in follow-up studies [74]. In people over 65 years, the rate of advanced adenomas of $7.6 \%$ is slightly higher than in younger people (6.1\%). In contrast, the size, histology, and distribution of colorectal polyps was found to be identical. Regarding C): From 2008 to today, 10 studies have addressed the frequency and relevance of extracolonic findings. As a result, E3 findings (further workup needed) and E4 findings (clinically severe consequences) are seen in $10-16 \%$ of patients and require additional examinations in $6-10 \%$ of cases [75]. In addition to quality standards regarding implementation and interpretation, the ESGAR (European Society of Gastrointestinal and Abdominal Radiology) and the ACR (American College of Radiology) defined a minimum number of CT colonoscopy examinations in training programs [76]. The finding standards relate both to intestinal abnormalities and to pathological findings and their significance outside the bowel. The U.S. Preventive Services Task Force as the key regulatory authority in the USA together with the CMS (Centers for Medicare and Medicaid Services) are currently reevaluating the available data regarding colon cancer prevention and in particular regarding virtual colonoscopy. Final recommendations in this regard are expected in 2015.

\section{Rectal cancer}

Current scientific topics highlight the value of imaging in the local staging of rectal cancer. The identification and validation of prognostically relevant image parameters that in the future will allow better and more precise evaluation of the course and prognosis and, if necessary, treatment and aftercare stratification are in the foreground here. A further topic involves the role of imaging after neoadjuvant radiochemotherapy. In addition to better evaluation of the local tumor finding and its differentiation from reactive treatment-induced changes, a search for surrogate parameters for prognosis, course, and treatment modifications in the framework of multiparametric MRI imaging is also performed here. The role of imaging in the case of relapse will not be further discussed here.

\section{Local staging of rectal cancer}

Depending on the position of the cancer, there are different minimum requirements for the preoperative diagnosis of spreading according to the current S3 guidelines from 2013 [71]. Taking into account some limitations in the differentiation of T1 substages (T1 sm1-3), T1 tumors of the rectum continue to be the domain of endoscopic ultrasound (recommendation level B, level of evidence $2 \mathrm{~b}$ - de novo). The staging of rectal cancer stage $\mathrm{T} 2$ and higher is more differentiated and also more complex [71]. The method of choice here is MRI, with 1.5 Tesla units with body coils representing the standard. To date, MRI at $3 \mathrm{~T}$ or the use of endorectal coils could not yield a significant diagnostic advantage [77, 78]. The minimum diagnostic requirements are sagittal and paraaxial, thin-slice (voxel size at least $3 \times 1 \times 1 \mathrm{~mm}^{3}$ ) T2weighted sequences and diffusion-weighted and contrastenhanced T1-weighted sequences $[78,79]$. In the case of low-lying rectal cancer, coronal T2 and contrast-enhanced T1-weighted sequences must be additionally performed for the evaluation of a possible infiltration of the sphincter complex/extralevator and intersphincter fascia [79]. $3 \mathrm{~T}$ MRI with the option to acquire $3 \mathrm{D}$ datasets of the pelvis will make it possible in the future to cover the entire T-staging with one sequence [78].

Extramural tumor extension largely determines the probability of distant metastases and is thus a decisive independent prognostic factor. In the current TNM classification for rectal cancer, a differentiated view of the T3 stage is currently becoming established. Based on the mesorectal infiltration depth, 4 subgroups are defined (T3a: $<1 \mathrm{~mm}$; T3b: $1-5 \mathrm{~mm}$; T3c: $>5-15 \mathrm{~mm}$; T3d: $>15 \mathrm{~mm}$ ) [80]. According to current data, MRI has an accuracy equivalent to that of histology [81]. Regardless of the nodal status, T3a and T3b tumors have a similar 5-year survival rate to that of $\mathrm{T} 2 \mathrm{tu}-$ mors with $85 \%$. This number drops to $54 \%$ for T3c tumors. Exact classification via MRI is thus to be considered a valid prognostic factor $[78,81]$.

The same is true for the obligatory determination of the tumor distance from the mesorectal fascia. In the case of a positive circumferential resection margin $(\mathrm{CRM}+)$ - per definition the distance of the tumor from the mesorectal fascia is less than $1 \mathrm{~mm}$ - the local relapse rate is 3.5 times and the mortality rate is 2 times higher than in patients with a negative circumferential resection margin (CRM-) [82]. According to the currently available data including T2w and $\mathrm{T} 1 \mathrm{w}$ post-contrast-enhanced images, MRI is capable of determining this distance with a sensitivity of $92 \%$ and a negative predictive value of $94 \%$ [83].

The determination of the so-called extramural vascular invasion (EMVI) via MRI was identified as a further independent prognostic factor. Such a situation can be assumed in 
approx. $25 \%$ of patients in stage UICC II and approximately $45 \%$ of patients in stage UICC III [84]. EMVI-positive patients with tumor infiltration into the perirectal vessels have a 4 times higher risk of distant metastases [85]. Sohn et al. [38] were able to recently show that the risk of distant metastases increases particularly in the case of infiltration of larger vessels ( $\geq 3 \mathrm{~mm}$ ). For MRI they found a sensitivity, specificity, and accuracy of $28 \%, 94 \%$, and $80 \%$, respectively ( $n=447$ patients, 79 with distant metastases) with respect to the evaluation of extramural vascular infiltration. MRI is currently the only preoperative imaging modality capable of visualizing extramural vascular invasion [79].

$\mathrm{N}$-staging continues to be a major challenge. The main problem is frequent micrometastases in normal-sized lymph nodes. In 1991, Dworak et al. showed that affected perirectal lymph nodes have an average diameter of only $3.3 \mathrm{~mm}$ [86]. Mönig et al. found tumor cell nests in lymph nodes with a diameter of $<5 \mathrm{~mm}$ in up to $53 \%$ of cases [87]. Due to the low tumor mass of micrometastases and the associated low tracer uptake, PET-CT has only a low sensitivity of $29 \%$ [88]. Only insufficient differentiation of benign or metastatic lymph nodes can currently be achieved with diffusionweighted sequences in MRI [89]. According to Birkhäuser et al., USPIO (ultrasmall superparamagnetic particles of iron oxide) contrast agents can detect lymph node infiltration with a specificity of $94-97 \%$ at least in prostate cancer or bladder cancer [90]. However, it remains to be seen whether the FDA and BfArM will approve USPIO contrast agents. Liu et al. [91] recently reviewed the value of dual-energy CT in the differentiation of benign and malignant lymph nodes in 55 rectal cancer patients. Compared to only the determination of the short-axis diameter of lymph nodes (SAD), the additional determination of the normalized iodine concentration (NIC) in this collective increased the accuracy of metastasis determination to $83 \%$. However, the importance of dual-energy imaging for the differentiation of benign and malignant lymph nodes is currently not sufficiently clarified. Even when using a routine MRI protocol, it is possible under consideration of certain criteria (form, margin definition, and lymph node signaling) to detect infiltrated lymph nodes with a relatively high accuracy of up to $85 \%$ [92]. In certain constellations, nodal status is less decisive for prognosis than previously assumed. Nodal-negative and N1 nodal-positive tumors have the same local relapse rates after neoadjuvant therapy and total mesorectal excision [93]. The same is true for T3a and T3b tumors with similar survival rates as T2 tumors regardless of nodal status [81]. Therefore, it remains to be seen in which cases exact preoperative N-staging is absolutely necessary for the planning of the proper therapy.

\section{Evaluation of disease course under neoadjuvant therapy}

Neoadjuvant radiochemotherapy of locally advanced rectal cancer has been a proven therapy for years. The downstaging rate is $60 \%$. Pathohistologically verified complete remission can even be achieved in $15-27 \%$ of cases. Neoadjuvant radiochemotherapy regimes have resulted in a significant improvement of the relapse rate and the survival rate. Moreover, the rate of sphincter/continence-preserving operations has risen.

A current challenge from a radiological standpoint is the MRI follow-up of the local finding under neoadjuvant ther- apy. Reactive changes of peritumoral and tumoral tissue with corresponding fibrotic and desmoplastic reactions during therapy complicate differentiation from vital tumor tissue. Accordingly, the accuracy of correct T-staging in this situation decreases to only $43-54 \%$ or correct $\mathrm{N}$-staging to $64-68 \%$ [78]. Overestimation of the T-stage can be expected in $38 \%$ of cases and a positive circumferential resection margin is incorrectly assumed in $56 \%$ of cases [78]. In cases of complete pathohistological remission after radiochemotherapy, the necessity for subsequent surgical treatment is currently being questioned and imaging biomarkers that are suitable for reliably identifying such a situation are being sought.

Scientific developments currently focus particularly on multiparametric imaging via MRI. The significance of diffusion imaging in terms of the evaluation of cell integrity and dynamic contrast-enhanced examinations in terms of the evaluation of microcirculation or vascular permeability is in the foreground. While tumor tissue has a high signal in diffusion-weighted sequences ( $\bullet$ Fig. 3 ) with a low signal in the ADC (apparent diffusion coefficient), the reverse is true in reactively changed tissue. Cancers that respond to therapy show an ADC signal increase in intermediate staging. Non-responders do not show any changes or only a minimal increase in the ADC signal. Birlik et al. [94] found significantly lower ADC values prior to the start of treatment in the group of non-responders compared to late responders and recently defined corresponding prognostic ADC threshold values of $b=600$ and $b=1000$. By comparing DWI before and after neoadjuvant therapy, treatment response can currently be derived with an accuracy of approx. $80-88 \%$ [95]. Texture analyses and their significance as biomarkers of tumor response at 3 Tesla and T2-weighted plain images are still in an early stage of development [96]. Current studies also compare the evaluation of tumor response via F18 FDG PET-CT and F-18 FLT PET-CT. While a significant SUVmax decrease after radiochemotherapy can be observed in both methods, significantly more histopathologically verified responders can be identified in metabolically negative F-18 FLT [97].

\section{Mesenteric bleeding and ischemia}

Both mesenteric bleeding and mesenteric ischemia are potentially life-threatening diseases. Therefore, quick diagnosis is extremely important. Due to its high availability and speed, modern cross-sectional imaging, in particular multidetector CT (MDCT), is predestined for the diagnosis of abdominal vessels. In contrast, angiography has been largely replaced by MDCT with respect to the diagnosis of mesenteric vascular diseases. However, it continues to play an important role in the therapeutic care of vascular diseases of the mesenterium in part due to the further development of the catheter technique.

\section{Mesenteric bleeding}

Intraabdominal bleeding is potentially life-threatening and can result in an acute abdomen but in general is a rare cause. Modern cross-sectional imaging has become increasingly important, particularly in the diagnosis of gastrointestinal bleeding [98].

While upper gastrointestinal (GI) bleeding is usually caused by ulcers, varices, and erosions, the most common causes 

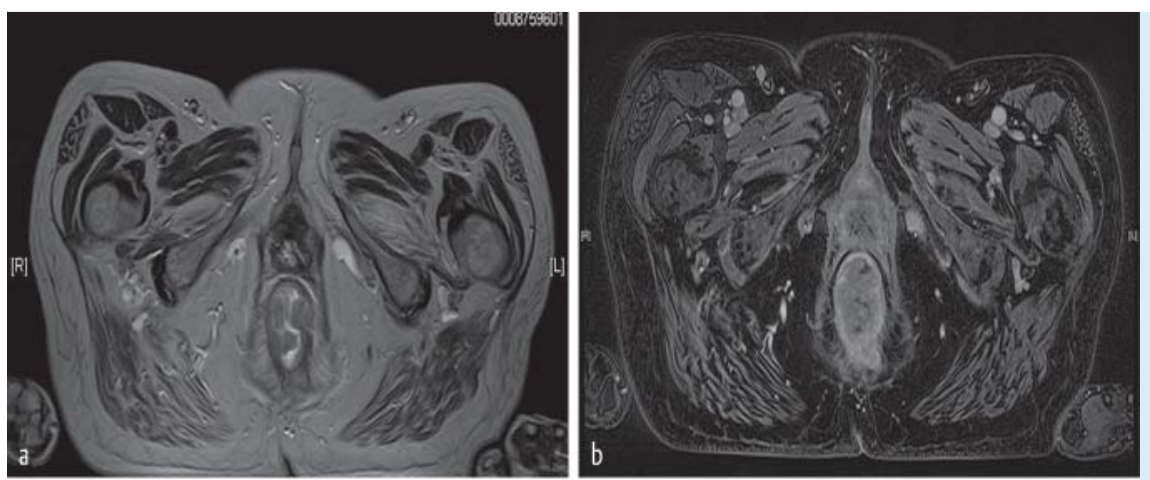

Fig. 3 Low-lying and difficult to delimit rectal cancer. In T2w a and T1w (fat saturation post-Gd, center), the tumor is unusually difficult to delimit. The fusion of T1w post-Gd with axial DWI images $c$ shows improved tumor detection and ability to evaluate tumor extension. The example (T1w postGd) of another tumor $\mathbf{d}$ shows its infiltration in to the extramural veins (EMVI).
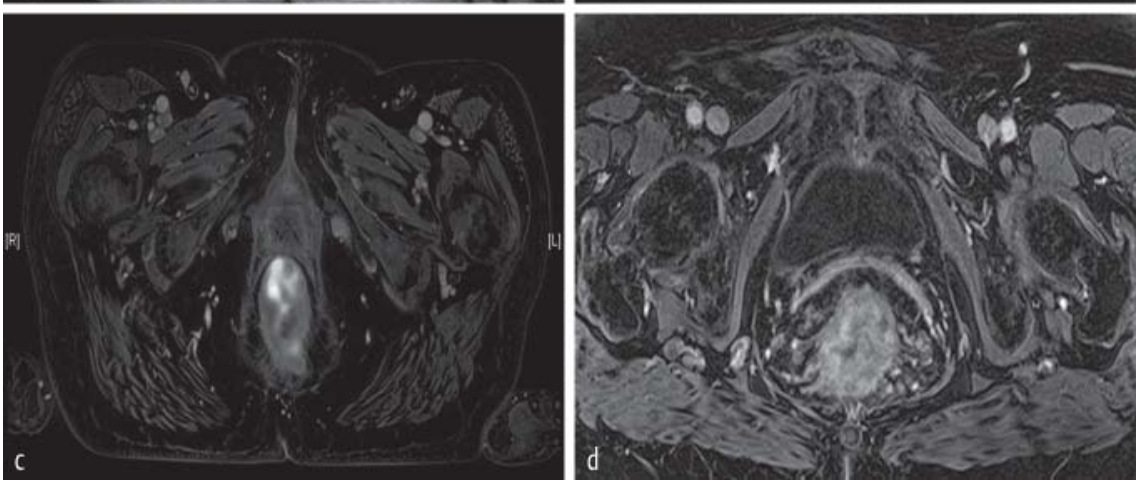

for lower gastrointestinal (GI) bleeding are diverticular bleeding, hemorrhoids, and angiodysplasia. Ell et al. [99] also developed the term mid-gastrointestinal bleeding describing the region distal to the major duodenal papilla to proximal to the ileocecal valve. While endoscopic methods in particular for lower GI bleeding continue to be very important for diagnosis and treatment, mid-GI bleeding is often the domain of cross-sectional imaging. MDCT with CTA has become significantly more important in recent years for the diagnosis of gastrointestinal bleeding. It was able to be shown on the basis of an animal model that MDCT can detect active bleeding starting at a bleeding rate of $0.5 \mathrm{ml} / \mathrm{min}$ [100]. This value is comparable with that of angiography. The sensitivity for detecting GI bleeding is approx. $85.2 \%$ and the specificity is $92.1 \%$ [101]. In addition, the location of bleeding can be identified with high diagnostic accuracy [102]. Active contrast extravasation can often be directly identified.

Intraperitoneal bleeding is caused, for example, by rupture of a visceral aneurysm as part of a rupture of parenchymatous abdominal organs or in the framework of bleeding due to arrosion caused by inflammatory processes or tumor infiltration. In pancreatitis, bleeding due to arrosion occurs in approx. $1.3 \%$ of cases [103]. Moreover, pseudoaneurysms representing a new potential source of bleeding can form. MDCT has largely replaced digital subtraction angiography (DSA) as the diagnostic method of choice in the search for intraperitoneal bleeding. Angiography is currently used more as a therapeutic tool than as a diagnostic instrument. Hyare et al. [104] were able to show that MDCT with CTA has a high sensitivity ( $94 \%$ ) and specificity ( $90 \%$ ) for the detection of arterial bleeding in pancreatitis. A study of the Ulm working group [105] detected the source of bleeding in 9 of 10 patients with intraperitoneal bleeding via MDCT.

\section{Mesenteric ischemia}

In 1926, A. J. Cokkins wrote the following about mesenteric ischemia: "The diagnosis is impossible, the prognosis hopeless and the treatment useless..." [106]. This statement was unfortunately often true at that time. Thankfully, radiology has been able to help to change at least the first point of the statement.

\section{Arterial occlusion}

Acute mesenteric ischemia is a rare but often life-threatening disease with a mortality rate between $60 \%$ and $80 \%$. The mortality rate can increase to $95 \%$ if the cause is thrombotic occlusion of the superior mesenteric artery [107]. It is therefore essential to detect arterial mesenteric ischemia before a transmural bowel infarction develops. The diagnosis of patients with clinical suspicion of arterial mesenteric ischemia includes lab tests (serum lactate and hyperkalemia) and imaging. In particular conventional angiography of the mesenteric arteries was the method of choice in the past for detecting an occlusion. However, the diagnostic algorithm has increasingly changed in recent years as a result of the development of CT. In particular, biphasic CT angiography (CTA) began to become increasingly established with the first published studies in 2001 [108, 109]. The advantage of MDCT is that not only the arteries and veins are visualized via CT angiography but also the perfusion of the abdominal and visceral organs can be shown. A pictorial essay by Wildermuth et al. [110] illustrates this very clearly. In an animal experiment with pigs, it was able to be shown that CTA can effectively differentiate between open and embolically occluded branches of the superior mesenteric artery with a positive predictive value of $92 \%$ [111]. In a further study in which CT units with 16 rows or more were used, excellent sensitivity and specificity values for the diagnosis of arterial mesenteric ischemia were able to be achieved [112]. This study additionally examined indirect 
signs of the presence of mesenteric ischemia. The most sensitive CT signs of mesenteric ischemia are the detection of intestinal pneumatosis or gas in the mesenteric vein or the portal vein. Both of these signs were $100 \%$ sensitive.

In contrast to mesenteric angiography using the catheter technique, MDCT has a series of further advantages: It is widely available, fast, noninvasive, and yields reproducible results. As such, it is ideally suited as the primary imaging modality for identifying patients who need immediate surgical therapy. Due to the high negative predictive value of multidetector CT, a watch-and-wait strategy can be used in patients with a negative CT. Such a diagnostic algorithm helps to save time and thus makes it possible to lower the mortality rate of patients with mesenteric arterial occlusions.

Special form: non-occlusive mesenteric ischemia (NOMI)

Already in 1995, Lock [113] defined NOMI as intestinal ischemia not caused by arteriosclerosis, arterial or venous thrombosis, arterial embolism, or vasculitis of the mesenteric vessels. This form of intestinal ischemia is therefore not based on a mechanical occlusion but rather on vasospastic events caused by various factors. Hypotension, intraabdominal pressure elevation, low cardiac output, and treatment with vasopressors or catecholamines represent the most common factors, i.e., concomitant circumstances that change hemodynamics and thus cause low blood flow to the mesenteric vascular system $[114,115]$. Primarily multimorbid patients are mainly affected by NOMI with a prevalence of $2-10 \%$, with a mortality rate of approx. $58 \%$ being defined here [116].

MDCT has also become important for the diagnosis of NOMI. According to recent data, its sensitivity of $96 \%$ is sufficient but specificities of only between $33 \%$ and $60 \%$ are achieved [117]. Angiography is the treatment method of choice, particularly for the treatment of non-perforated NOMI. Potent vasodilators can be locally applied over multiple days so that the non-occlusive ischemia can be treated [118].

Venous occlusion

With $5-15 \%$ of cases, venous occlusion ranks third after arterial occlusion and non-occlusive disease as a cause of mesenteric ischemia. Portal hypertension and portal vein thrombosis, abdominal trauma, previous abdominal surgical interventions, inflammation in the abdominal cavity, and hypercoagulability are considered to be predisposing factors [119]. Approximately $20 \%$ of mesenteric vein thromboses remain etiologically unclarified and are referred to as idiopathic. The disease can take different forms. In addition to a chronic form that is usually clinically inapparent, the subacute form in which patients complain of abdominal pain for weeks and months is differentiated from acute venous mesenteric ischemia. The acute course is clinically similar to the arterial form of mesenteric ischemia. The symptoms coincide with the clinical picture of an acute abdomen. The main symptom is abdominal pain in more than $90 \%$ of patients [120]. Bloody diarrhea, hematochezia, and hematemesis are signs of a mesenteric infarction that has already occurred.

Analogously to arterial mesenteric ischemia, both direct detection of a venous mesenteric occlusion on CT as well as in- direct signs of stenosis are seen. These relatively nonspecific signs can be dilated intestinal loops, ascites, and mesenteric fatty tissue imbibition. Intestinal wall changes are also ultimately nonspecific. Intestinal wall thickening with a lack or at least reduced contrast enhancement and a target sign is often seen [121 - 123]. The lack of contrast enhancement of the intestinal wall with detection of intramural gas formation or intestinal gas in the mesenteric outflow vessel is an indication of transmural ischemia. Specific signs associated with transmural ischemia include an indistinct intestinal wall and larger quantities of ascites [124]. Depending on the location of the occlusion of the venous outflow in the periphery, morphologically normal and pathological intestinal loops can occur next to one another. In addition to indirect signs, direct thrombus detection can be achieved via contrast-enhanced MDCT. CT is a highly specific examination modality with values of $100 \%[112,125]$ and also a negative predictive value of $100 \%$. However, the sensitivity is significantly lower and depending on the study is only up to $21 \%$ [112].

Angiography does not play a role in the diagnosis of mesenteric or portal vein thrombosis and also the radiological intervention options are very limited even if small case series have promising results [126].

\section{Varia in the gastrointestinal tract \\ $\nabla$}

Acute intestinal graft versus host disease (GvHD) is a serious complication of allogenic stem cell transplantation and occurs in $30-75 \%$ of cases. A Mannheim working group described the typical clinical picture on MRI based on the data of 9 patients with confirmed GvHD [127]. Extensive wall thickening of the intestine is typical for GvHD with the terminal ileum always being affected in the examined group. In addition, the submucosa was not enhanced in all cases while strong contrast enhancement was seen in the mucosa. The Regensburg working group of Schreyer was able to show using CEUS (contrast-enhanced ultrasound) in 2 studies involving patients with GvHD that a transfer of microbubbles to the intestinal lumen in patients with acute GvHD probably due to the damaged mucosal barrier can be detected [128, 129]. With a positive predictive value (PPV) of $100 \%$, this method could be a good specific instrument for early and specific diagnosis of GvHD and for differential diagnosis from viral enteritis, but further evaluation in a larger cohort is not yet available.

Conventional radiology in gastrointestinal and abdominal radiology was a further topic that was critically addressed and discussed in recent literature in Germany. Therefore, the Regensburg working group was able to show that there was no diagnostic added value of scans acquired in a lying position in the retrospective analysis of 2148 patients who underwent a conventional survey scan of the abdomen in a standing position or in a left-lateral position with an additional scan in a lying position [130]. A pathological finding (obstruction, free air, etc.) was seen in $10.8 \%(n=232)$ of patients on these conventional scans. Even if in total $3.5 \%$ $(n=75)$ more anatomical structures or foreign material was able to be detected on images acquired in a lying position, this information was not diagnostically relevant in a single case so that routine acquisition of images in a lying position 
as a supplement to images in a standing position or in a leftlateral position is no longer to be viewed as indicated in the majority of cases. A further publication from the same working group retrospectively examined the value of conventional fluoroscopy of the gastrointestinal passage in 300 patients of a university hospital [131]. In this study the authors found that a further diagnostic imaging method such as endoscopy, CT, or ultrasound was initiated in over $87 \%$ of patients who underwent gastrointestinal passage prior to a change in diagnosis or treatment. The already known diagnosis such as intestinal stenosis or partial obstruction was confirmed in a majority of patients with the patients being exposed to an average radiation dose of $7 \mathrm{mSv}$ which is approximately in the range of modern CT systems. Based on the analysis, the authors concluded that the indication for gastrointestinal passage should be made extremely conservatively and critically given the availability of modern cross-sectional imaging methods such as CT, MRI, and ultrasound since indicative therapy-relevant decisions are made based on conventional methods with relatively high radiation exposure in only rare cases.

Several publications analyzing the value of conventional abdominal radiography compared to low-dose CT in body packers provide a similar critical analysis of conventional techniques [132, 133]. In principle, the studies determine that the detection of illegal packets of drugs in the bowel is more successful with low-dose CT than with conventional abdominal radiography. The fact that low-dose CT uses a lower biological radiation dose than conventional radiography with the same diagnostic value is interesting. Average values of $2 \mathrm{mSv}$ for conventional radiography compared to $1.2 \mathrm{mSv}$ for low-dose CT in women are specified here as an example. This data can be largely extrapolated from "healthy" body packers to patients with pathological changes.

\section{Summary and further developments \\ $\nabla$}

In recent years, there have been notable scientific and clinical advances in abdominal radiology in Germany that have significantly influenced global radiological literature. A definite paradigm shift in the diagnosis of the esophagus and stomach was able to develop based on this new literature so that cross-sectional imaging methods such as MRI and primarily MSCT with their high resolution are put at least on par with endosonographic methods in some cases. This literature and thus evidence-based data were able to be included in the new S3 guidelines for esophageal and gastric cancer. With respect to the diagnosis of the small bowel, a similarly strong influence of the current scientific literature on the updated care guidelines was noted. The scientific focus in recent years was on the diagnosis and more precise evaluation of chronic inflammatory bowel diseases. The scientific focus on radiation-free methods such as MRI and ultrasound was the main driving force for clinical care and diagnosis in Germany and Europe so that MRI in addition to ultrasound was specified in the German guidelines on Crohn's disease in 2008 as the basic examination for this disease of typically young patients [45]. Fortunately, these findings have been integrated in European and global recommendations and guidelines in recent years. New techniques such as movement imaging in MRI as well as diffu- sion-weighted imaging of the bowel for the detection of inflammatory changes are interesting examples of the optimization of existing protocols that will hopefully soon become established in clinical practice given sufficient evidence from studies.

In the diagnosis of the colon, virtual colonoscopy has replaced conventional intestinal examinations. However, there is still a limited indication spectrum (stenosed tumors, contraindications to colonoscopy) according to the guidelines. A reevaluation of the literature regarding prevention and screening by the CMS (Centers for Medicare and Medicaid Services) is expected in the USA over the course of 2015. In the diagnosis of rectal cancer, primarily high-resolution MRI plays a decisive role in treatment stratification and staging. Diffusion techniques may allow potential tools for the evaluation of tumor response for treatment.

In the diagnosis of mesenteric ischemia and bleeding, multidetector CT (MDCT) is increasingly becoming the established method of choice. Modern cross-sectional imaging methods such as MRI of the abdomen and contrast-enhanced ultrasound (CEUS) can be a specific diagnostic agent also in the evaluation of GVHD and its differential diagnosis. The influence of traditional conventional abdominal radiography is further reduced under consideration of the high diagnostic performance of modern cross-sectional imaging methods such as CT, MRI, and CEUS with low or no radiation exposure.

\footnotetext{
Affiliations

Department of Radiology, University Hospital Regensburg, Germany

2 Clinic for Radiology, Clemens Hospital, Münster, Germany

Department of Radiology, University Hospital Essen, Germany

4 Department of Diagnostic and Interventional Radiology, Konstanz, Hospital, Germany

5 Institute of Radiology, Technical University Munich, Germany

${ }^{6}$ Department of Diagnostic and Interventional Radiology, University Hospital Heidelberg, Germany

Diagnostic München - Diagnostic Imaging Center, Munich, Germany
}

\section{References}

1 Blank S, Blaker $H$, Schaible A et al. Impact of pretherapeutic routine clinical staging for the individualization of treatment in gastric cancer patients. Langenbeck's archives of surgery/Deutsche Gesellschaft fur Chirurgie 2012; 397: 45 - 55

2 Blank $S$, Lordick F, Dobritz $M$ et al. A reliable risk score for stage IV esophagogastric cancer. European journal of surgical oncology 2013; 39: $823-830$

3 Blank S, Stange A, Sisic L et al. Preoperative therapy of esophagogastric cancer: the problem of nonresponding patients. Langenbeck's archives of surgery/Deutsche Gesellschaft fur Chirurgie 2013; 398: $211-220$

4 Heger U, Blank S, Wiecha $C$ et al. Is preoperative chemotherapy followed by surgery the appropriate treatment for signet ring cell containing adenocarcinomas of the esophagogastric junction and stomach? Annals of surgical oncology 2014; 21: 1739-1748

5 Grenacher L, Schwarz M, Lordick F et al. S3 guideline - diagnosis and treatment of gastric carcinoma: relevance for radiologic imaging. Fortschr Röntgenstr 2012; 184: 706 - 712

6 Moehler M, Al-Batran SE, Andus T et al. German S3-guideline "Diagnosis and treatment of esophagogastric cancer". Zeitschrift fur Gastroenterologie 2011; 49: 461 - 531

$7 \mathrm{Kim} \mathrm{TJ,} \mathrm{Kim} \mathrm{HY,} \mathrm{Lee} \mathrm{KW} \mathrm{et} \mathrm{al.} \mathrm{Multimodality} \mathrm{assessment} \mathrm{of} \mathrm{esophageal}$ cancer: preoperative staging and monitoring of response to therapy. Radiographics 2009; 29: $403-421$

8 Moreto M. Diagnosis of esophagogastric tumors. Endoscopy 2005; 37 : $26-32$ 
9 Peeters MLT, Vlayen J et al. Wetenschappelijke ondersteuning van het College voor Oncologie: een nationale praktijkrichtlijn voor de aanpak van slokdarm- en maagkanker Brussel. Federaal Kenniscentrum voor de Gezondheidszorg Centre fédéral d'expertise des soins de santé 2008, Available from http://kce.fgov.be/sites/default/files/page_documents/d20081027316.pdf

10 Quint LE, Bogot NR. Staging esophageal cancer. Cancer imaging 2008; 8 Spec No A: S33-S42

11 SIGN. Management of oesophageal and gastric cancer - A national clinical guideline; 2006, Available from: http://www.sign.ac.uk/pdf/sign87. pdf

12 Wang KK, Wongkeesong M, Buttar NS. American Gastroenterological Association technical review on the role of the gastroenterologist in the management of esophageal carcinoma. Gastroenterology 2005; 128: $1471-1505$

13 Puli SR, Batapati Krishna Reddy J, Bechtold ML et al. How good is endoscopic ultrasound for TNM staging of gastric cancers? A meta-analysis and systematic review. WJG 2008; 14: 4011-4019

14 Thosani N, Singh H, Kapadia A et al. Diagnostic accuracy of EUS in differentiating mucosal versus submucosal invasion of superficial esophageal cancers: a systematic review and meta-analysis. Gastrointestinal endoscopy 2012; 75: 242 - 253

15 van Vliet EP, van der Lugt A, Kuipers EJ et al. Ultrasound, computed tomography, or the combination for the detection of supraclavicular lymph nodes in patients with esophageal or gastric cardia cancer: a comparative study. Journal of surgical oncology 2007; 96: 200-206

16 Schreurs LM, Verhoef CC, van der Jagt EJ et al. Current relevance of cervical ultrasonography in staging cancer of the esophagus and gastroesophageal junction. European journal of radiology 2008; 67: $105-111$

17 Van Overhagen H, Lameris JS, Berger MY et al. Improved assessment of supraclavicular and abdominal metastases in oesophageal and gastrooesophageal junction carcinoma with the combination of ultrasound and computed tomography. The British journal of radiology 1993; 66: $203-208$

18 Omloo JM, van Heijl M, Smits NJ et al. Additional value of external ultrasonography of the neck after CT and PET scanning in the preoperative assessment of patients with esophageal cancer. Digestive surgery 2009; $26: 43-49$

19 van Overhagen $H$, Lameris JS, Berger MY et al. Supraclavicular lymph node metastases in carcinoma of the esophagus and gastroesophageal junction: assessment with CT, US, and US-guided fine-needle aspiration biopsy. Radiology 1991; 179: 155-158

20 van Overhagen H, Lameris JS, Berger MY et al. Assessment of distant metastases with ultrasound-guided fine-needle aspiration biopsy and cytologic study in carcinoma of the esophagus and gastroesophageal junction. Gastrointestinal radiology 1992; 17: 305-310

21 Dietrich CF. Characterisation of focal liver lesions with contrast enhanced ultrasonography. European journal of radiology 2004; 51: S9-17

22 Oldenburg A, Albrecht T. Baseline and contrast-enhanced ultrasound of the liver in tumor patients. Ultraschall in der Medizin 2008; 29: $488-498$

23 Piscaglia F, Corradi F, Mancini $M$ et al. Real time contrast enhanced ultrasonography in detection of liver metastases from gastrointestinal cancer. BMC Cancer 2007; 7: 171

24 Albrecht T, Blomley MJ, Burns PN et al. Improved detection of hepatic metastases with pulse-inversion US during the liver-specific phase of SHU 508A: multicenter study. Radiology 2003; 227: 361 - 370

25 Cantisani V, Ricci P, Erturk $M$ et al. Detection of hepatic metastases from colorectal cancer: prospective evaluation of gray scale US versus SonoVue(R) low mechanical index real time-enhanced US as compared with multidetector-CT or Gd-BOPTA-MRI. Ultraschall in der Medizin 2010; 31: 500-505

26 Claudon M, Cosgrove D, Albrecht $T$ et al. Guidelines and good clinical practice recommendations for contrast enhanced ultrasound (CEUS) - update 2008. Ultraschall in der Medizin 2008; 29: 28-44

27 Dietrich CF. Comments and illustrations regarding the guidelines and good clinical practice recommendations for contrast-enhanced ultrasound (CEUS) - update 2008. Ultraschall in der Medizin 2008; 29 : S188-S202

28 Dietrich CF, Kratzer W, Strobe $D$ et al. Assessment of metastatic liver disease in patients with primary extrahepatic tumors by contrast-enhanced sonography versus CT and MRI. WJG 2006; 12: 1699-1705
29 Kamel IR, Fishman EK. Recent advances in CT imaging of liver metastases. Cancer journal 2004; 10: 104-120

30 Makarawo TP, Negussie E, Malde S et al. Water as a contrast medium: a re-evaluation using the multidetector-row computed tomography. The American surgeon 2013; 79: 728 - 733

31 Ba-Ssalamah A, Matzek W, Baroud S et al. Accuracy of hydro-multidetector row $\mathrm{CT}$ in the local T staging of oesophageal cancer compared to postoperative histopathological results. Eur Radiol 2011; 21: 2326 2335

32 Kinkel $K, L u Y$, Both $M$ et al. Detection of hepatic metastases from cancers of the gastrointestinal tract by using noninvasive imaging methods (US, CT, MR imaging, PET): a meta-analysis. Radiology 2002; 224: $748-756$

33 Kwee RM, Kwee TC. Imaging in local staging of gastric cancer: a systematic review. Journal of clinical oncology 2007; 25: 2107-2116

34 Takizawa K, Matsuda T, Kozu T et al. Lymph node staging in esophageal squamous cell carcinoma: a comparative study of endoscopic ultrasonography versus computed tomography. Journal of gastroenterology and hepatology 2009; 24: 1687 -1691

35 Abstracts of the Annual Scientific Meeting of the Association of Upper Gastrointestinal Surgeons for Great Britain and Ireland. September 1516, 2011 Belfast, United Kingdom. The British journal of surgery 2011; 98: $1-55$

36 Anzidei M, Napoli A, Zaccagna F et al. Diagnostic performance of 64MDCT and 1.5-T MRI with high-resolution sequences in the T staging of gastric cancer: a comparative analysis with histopathology. La Radiologia medica 2009; 114: $1065-1079$

37 Hammerstingl R, Huppertz A, Breuer J et al. Diagnostic efficacy of gadoxetic acid (Primovist)-enhanced MRI and spiral CT for a therapeutic strategy: comparison with intraoperative and histopathologic findings in focal liver lesions. Eur Radiol 2008; 18: 457-467

38 Sohn KM, Lee JM, Lee SY et al. Comparing MR imaging and CT in the staging of gastric carcinoma. American journal of roentgenology 2000; 174: $1551-1557$

39 Lauenstein TC, Goehde SC, Herborn CU et al. Whole-body MR imaging: evaluation of patients for metastases. Radiology 2004; 233: 139-148

40 Wong $R$, Malthaner $R$. Esophageal cancer: a systematic review. Current problems in cancer 2000; 24: 297-373

41 Scheibl K, Schreyer AG, Kullmann $F$ et al. Magnetic resonance imaging gastrography: evaluation of the dark lumen technique compared with conventional gastroscopy in patients with malignant gastric disease. Investigative radiology 2005; 40: $164-172$

42 Weber MA, Bender K, von Gall CC et al. Assessment of diffusion-weighted MRI and $18 \mathrm{~F}$-fluoro-deoxyglucose PET/CT in monitoring early response to neoadjuvant chemotherapy in adenocarcinoma of the esophagogastric junction. Journal of gastrointestinal and liver diseases 2013; 22: 45-52

43 Heeren PA, Jager PL, Bongaerts F et al. Detection of distant metastases in esophageal cancer with (18)F-FDG PET. Journal of nuclear medicine 2004; 45: 980-987

44 Barber TW, Duong CP, Leong T et al. 18F-FDG PET/CT has a high impact on patient management and provides powerful prognostic stratification in the primary staging of esophageal cancer: a prospective study with mature survival data. Journal of nuclear medicine 2012; 53: $864-871$

45 Schreyer AG, Ludwig D, Koletzko S et al. Aktualisierte S 3-Leitlinie zur Diagnostik des Morbus Crohn - radiologische Untersuchungstechniken. Fortschr Röntgenstr 2010; 182: 116-121

46 Hoffmann JC, Autschbach F, Bokemeyer B et al. Kurzfassung der aktualisierten S3-Leitlinie der DGVS und des Kompetenznetzwerkes CED zur Diagnostik und Behandlung des Morbus Crohn. Deutsche medizinische Wochenschrift 2008; 133: 1924-1929

47 Friedrich C, Fajfar A, Pawlik M et al. Magnetic resonance enterography with and without biphasic contrast agent enema compared to conventional ileocolonoscopy in patients with Crohn's disease. Inflammatory bowel diseases 2012; 18: $1842-1848$

48 Schreyer AG, Menzel C, Friedrich C et al. Comparison of high-resolution ultrasound and MR-enterography in patients with inflammatory bowel disease. World journal of gastroenterology 2011; 17: 1018-1025

49 Girlich C, Jung EM, Huber E et al. Comparison between preoperative quantitative assessment of bowel wall vascularization by contrast-enhanced ultrasound and operative macroscopic findings and results of histopathological scoring in Crohn's disease. Ultraschall in der Medizin 2011; 32: $154-159$ 
50 Girlich C, Schacherer D, Jung EM et al. Comparison between a clinical activity index (Harvey-Bradshaw-Index), laboratory inflammation markers and quantitative assessment of bowel wall vascularization by contrast-enhanced ultrasound in Crohn's disease. European journal of radiology 2012; 81: 1105-1109

51 Schreyer AG, Hoffstetter P, Daneschnejad M et al. Comparison of conventional abdominal CT with MR-enterography in patients with active Crohn's disease and acute abdominal pain. Academic radiology 2010; 17: $352-357$

52 Schill G, Iesalnieks I, Haimerl M et al. Assessment of disease behavior in patients with Crohn's disease by MR enterography. Inflammatory bowel diseases 2013; 19: 983 - 990

53 Schleder S, Pawlik M, Wiggermann P et al. Interobserver agreement in $\mathrm{mr}$ enterography for diagnostic assessment in patients with Crohn's disease. Fortschr Röntgenstr 2013; 185: 992 - 997

54 Lenze F, Wessling J, Bremer $J$ et al. Detection and differentiation of inflammatory versus fibromatous Crohn's disease strictures: prospective comparison of 18F-FDG-PET/CT, MR-enteroclysis, and transabdominal ultrasound versus endoscopic/histologic evaluation. Inflammatory bowel diseases 2012; 18: 2252-2260

55 Holtmann MH, Uenzen M, Helisch A et al. 18F-Fluorodeoxyglucose positron-emission tomography (PET) can be used to assess inflammation non-invasively in Crohn's disease. Digestive diseases and sciences 2012; 57: 2658-2668

56 Schreiter NF, Maurer M, Pape UF et al. Detection of neuroendocrine tumours in the small intestines using contrast-enhanced multiphase Ga68 DOTATOC PET/CT: the potential role of arterial hyperperfusion. Radiology and oncology 2014; 48: 120-126

57 Kinner S, Blex S, Maderwald S et al. Addition of diffusion-weighted imaging can improve diagnostic confidence in bowel MRI. Clinical radiology 2014; 69: $372-377$

58 Sirin S, Kathemann S, Schweiger B et al. Magnetic resonance colonography including diffusion-weighted imaging in children and adolescents with inflammatory bowel disease: do we really need intravenous contrast? Investigative radiology 2015; 50: 32 - 39

59 Neubauer H, Pabst T, Dick A et al. Small-bowel MRI in children and young adults with Crohn disease: retrospective head-to-head comparison of contrast-enhanced and diffusion-weighted MRI. Pediatric radiology 2013; 43: $103-114$

60 Bickelhaupt S, Cattin R, Froehlich JM et al. Automatic detection of small bowel contraction frequencies in motility plots using lomb-scargle periodogram and sinus-fitting method-initial experience. Magnetic resonance in medicine 2013

61 Bickelhaupt S, Froehlich JM, Cattin $R$ et al. Software-assisted quantitative analysis of small bowel motility compared to manual measurements. Clinical radiology 2014; 69: 363 - 371

62 Cullmann JL, Bickelhaupt S, Froehlich JM et al. MR imaging in Crohn's disease: correlation of MR motility measurement with histopathology in the terminal ileum. Neurogastroenterology and motility: the official journal of the European Gastrointestinal Motility Society 2013; 25: 749 - e577

63 Bickelhaupt S, Pazahr S, Chuck N et al. Crohn's disease: small bowel motility impairment correlates with inflammatory-related markers C-reactive protein and calprotectin. Neurogastroenterology and motility 2013; 25: $467-473$

64 Bickelhaupt S, Froehlich JM, Cattin R et al. Differentiation between active and chronic Crohn's disease using MRI small-bowel motility examinations - initial experience. Clinical radiology 2013; 68: 1247 1253

65 Bickelhaupt S, Wurnig M, Boss A et al. Correlation between morphological expansion and impairment of intra- and prelesionary motility in inflammatory small bowel lesions in patients with Crohn's disease preliminary data. European journal of radiology 2014; 83: 1044-1050

66 Bickelhaupt S, Wurnig MC, Lesurtel M et al. Quantitative in vivo analysis of small bowel motility using MRI examinations in mice - proof of concept study. Laboratory animals 2014

67 Hahnemann ML, Nensa F, Kinner S et al. Motility mapping as evaluation tool for bowel motility: Initial results on the development of an automated color-coding algorithm in cine MRI. Journal of magnetic resonance imaging 2014

68 Hahnemann ML, Nensa F, Kinner S et al. Improved Detection of Inflammatory Bowel Disease by Additional Automated Motility Analysis in Magnetic Resonance Imaging. Investigative radiology 2014

69 Adamek HE, Schantzen W, Rinas $U$ et al. Ultra-high-field magnetic resonance enterography in the diagnosis of ileitis (Neo-)terminalis: a prospective study. Journal of clinical gastroenterology 2012; 46 $311-316$

70 Frericks BB, Kuhl AA, Loddenkemper $C$ et al. Gadofluorine M-enhanced magnetic resonance imaging of inflammatory bowel disease: quantitative analysis and histologic correlation in a rat model. Investigative radiology 2011; 46: $478-485$

71 Pox C, Aretz S, Bischoff SC et al. S3-guideline colorectal cancer version 1.0. Zeitschrift für Gastroenterologie 2013; 51: $753-854$

72 Spada C, Stoker J, Alarcon 0 et al. Clinical indications for computed tomographic colonography: European Society of Gastrointestinal Endoscopy (ESGE) and European Society of Gastrointestinal and Abdominal Radiology (ESGAR) Guideline. Endoscopy 2014; 46: 897-915

73 Berrington de Gonzalez A, Kim KP, Yee J. CT colonography: perforation rates and potential radiation risks. Gastrointestinal endoscopy clinics of North America 2010; 20: 279-291

74 Johnson $C D$, Chen $M H$, Toledano AY et al. Accuracy of CT colonography for detection of large adenomas and cancers. The New England journal of medicine 2008; 359: 1207 - 1217

75 Pooler BD, Kim DH, Lam VP et al. CT Colonography Reporting and Data System (C-RADS): benchmark values from a clinical screening program. American journal of roentgenology 2014; 202: 1232 - 1237

76 Neri E, Halligan S, Hellstrom $M$ et al. The second ESGAR consensus statement on CT colonography. Eur Radiol 2013; 23: 720 - 729

77 Maas M, Lambregts DM, Lahaye MJ et al. T-staging of rectal cancer: accuracy of 3.0 Tesla MRI compared with 1.5 Tesla. Abdom Imaging 2012; 37: $475-481$

78 Wietek BM, Kratt T. Current MRI staging of rectal cancer. RoFo: Fortschritte auf dem Gebiete der Rontgenstrahlen und der Nuklearmedizin 2012; 184: 992 - 1001

79 Nougaret S, Reinhold C, Mikhael HW et al. The use of MR imaging in treatment planning for patients with rectal carcinoma: have you checked the "DISTANCE"? Radiology 2013; 268: 330-344

80 Smith N, Brown G. Preoperative staging of rectal cancer. Acta oncologica $2008 ; 47: 20-31$

81 Group MS. Extramural depth of tumor invasion at thin-section MR in patients with rectal cancer: results of the MERCURY study. Radiology 2007: 243: 132 - 139

82 Birbeck KF, Macklin CP, Tiffin NJ et al. Rates of circumferential resection margin involvement vary between surgeons and predict outcomes in rectal cancer surgery. Annals of surgery 2002; 235: 449-457

83 Group MS. Diagnostic accuracy of preoperative magnetic resonance imaging in predicting curative resection of rectal cancer: prospective observational study. Bmj 2006; 333: 779

84 Chand $M$, Bhangu A, Wotherspoon A et al. EMVI-positive stage II rectal cancer has similar clinical outcomes as stage III disease following preoperative chemoradiotherapy. Annals of oncology 2014; 25: 858-863

85 Smith NJ, Barbachano Y, Norman AR et al. Prognostic significance of magnetic resonance imaging-detected extramural vascular invasion in rectal cancer. The British journal of surgery 2008; 95: 229-236

86 Dworak 0 . Morphology of lymph nodes in the resected rectum of patients with rectal carcinoma. Pathology, research and practice 1991; 187: 1020 - 1024

87 Monig SP, Baldus SE, Zirbes TK et al. Lymph node size and metastatic infiltration in colon cancer. Annals of surgical oncology 1999; 6: $579-581$

88 von Schulthess GK, Steinert HC, Hany TF. Integrated PET/CT: current applications and future directions. Radiology 2006; 238: 405-422

89 Heijnen LA, Lambregts DM, Mondal D et al. Diffusion-weighted MR imaging in primary rectal cancer staging demonstrates but does not characterise lymph nodes. Eur Radiol 2013; 23: 3354-3360

90 Birkhauser FD, Studer UE, Froehlich JM et al. Combined ultrasmall superparamagnetic particles of iron oxide-enhanced and diffusionweighted magnetic resonance imaging facilitates detection of metastases in normal-sized pelvic lymph nodes of patients with bladder and prostate cancer. European urology 2013; 64: 953 -960

91 Liu H, Yan F, Pan Z et al. Evaluation of dual energy spectral CT in differentiating metastatic from non-metastatic lymph nodes in rectal cancer: Initial experience. European journal of radiology 2015; 84: $228-234$

92 Brown G, Richards CJ, Bourne MW et al. Morphologic predictors of lymph node status in rectal cancer with use of high-spatial-resolution MR imaging with histopathologic comparison. Radiology 2003; 227: $371-377$

93 Hermanek P, Merkel S, Fietkau R et al. Regional lymph node metastasis and locoregional recurrence of rectal carcinoma in the era of TME [cor- 
rected] surgery. Implications for treatment decisions. International journal of colorectal disease 2010; 25: 359-368

94 Birlik B, Obuz F, Elibol FD et al. Diffusion-Weighted Mri and Mr- volumetry - in the Evaluation of Tumor Response After Preoperative Chemoradiotherapy in Patients with Locally Advanced Rectal Cancer. Magnetic resonance imaging 2014, Epub 2014 Nov 13

95 Lambregts DM, Maas M, Riedl RG et al. Value of ADC measurements for nodal staging after chemoradiation in locally advanced rectal cancera per lesion validation study. Eur Radiol 2011; 21: 265-273

96 De Cecco CN, Ganeshan B, Ciolina M et al. Texture Analysis as Imaging Biomarker of Tumoral Response to Neoadjuvant Chemoradiotherapy in Rectal Cancer Patients Studied with 3-T Magnetic Resonance. Investigative radiology 2015; 50: 239-245

97 Rendl G, Rettenbacher L, Holzmannhofer J et al. Assessment of response to neoadjuvant radiochemotherapy with F-18 FLT and F-18 FDG PET/ CT in patients with rectal cancer. Annals of nuclear medicine 2015; 29: $284-294$

98 Juchems MS, Aschoff AJ. Diagnostics of vascular diseases as a cause for acute abdomen. Der Radiologe 2010; 50: 246-251

99 Ell C, May A. Mid-gastrointestinal bleeding: capsule endoscopy and push-and-pull enteroscopy give rise to a new medical term. Endoscopy 2006 ; $38: 73-75$

100 Kuhle WG, Sheiman RG. Detection of active colonic hemorrhage with use of helical CT: findings in a swine model. Radiology 2003; 228: $743-752$

101 Garcia-Blazquez V, Vicente-Bartulos A, Olavarria-Delgado A et al. Accuracy of CT angiography in the diagnosis of acute gastrointestinal bleeding: systematic review and meta-analysis. Eur Radiol 2013; 23: $1181-1190$

102 Tew K, Davies RP, Jadun CK et al. MDCT of acute lower gastrointestinal bleeding. American journal of roentgenology 2004; 182: 427-430

103 Balthazar EJ, Fisher LA. Hemorrhagic complications of pancreatitis: radiologic evaluation with emphasis on CT imaging. Pancreatology 2001; 1 : 306-313

104 Hyare H, Desigan S, Nicholl H et al. Multi-section CT angiography compared with digital subtraction angiography in diagnosing major arterial hemorrhage in inflammatory pancreatic disease. European journal of radiology 2006; 59: 295-300

105 Jaeckle T, Stuber G, Hoffmann MH et al. Detection and localization of acute upper and lower gastrointestinal (GI) bleeding with arterial phase multi-detector row helical CT. Eur Radiol 2008; 18: $1406-$ 1413

106 Boley SJ, Brandt LJ, Sammartano RJ. History of mesenteric ischemia. The evolution of a diagnosis and management. Surg Clin North Am 1997; 77: $275-288$

107 Inderbitzi R, Wagner HE, Seiler C et al. Acute mesenteric ischaemia. Eur J Surg 1992; 158: 123-126

108 Horton KM, Fishman EK. Multi-detector row CT of mesenteric ischemia: can it be done? Radiographics 2001; 21: 1463-1473

109 Wiesner W, Mortele KJ, Glickman JN et al. Pneumatosis intestinalis and portomesenteric venous gas in intestinal ischemia: correlation of CT findings with severity of ischemia and clinical outcome. American journal of roentgenology 2001; 177: 1319-1323

110 Wildermuth S, Leschka S, Alkadhi H et al. Multislice CT in the pre- and postinterventional evaluation of mesenteric perfusion. Eur Radiol 2005; $15: 1203-1210$

111 Rosow DE, Sahani $D$, Strobel $O$ et al. Imaging of acute mesenteric ischemia using multidetector CT and CT angiography in a porcine model. Journal of gastrointestinal surgery 2005; 9: 1262-1274; discussion 74-75

112 Aschoff AJ, Stuber G, Becker BW et al. Evaluation of acute mesenteric ischemia: accuracy of biphasic mesenteric multi-detector $\mathrm{CT}$ angiography. Abdom Imaging 2009; 34: 345-357
113 Lock G, Scholmerich J. Non-occlusive mesenteric ischemia. Hepatogastroenterology 1995; 42: 234-239

114 Menon NJ, Amin AM, Mohammed A et al. Acute mesenteric ischaemia. Acta chirurgica Belgica 2005; 105: 344-354

115 Rellecke $P$, Strauer BE. Concomitant cardiovascular conditions in intestinal illness. Der Internist 2007; 48: 290-296

116 Stockmann H, Roblick UJ, Kluge $N$ et al. Diagnosis and therapy of non-occlusive mesenteric ischemia (NOMI). Zentralblatt fur Chirurgie 2000; 125: $144-151$

117 Kwok HC, Dirkzwager I, Duncan DS et al. The accuracy of multidetector computed tomography in the diagnosis of non-occlusive mesenteric ischaemia in patients after cardiovascular surgery. Critical care and resuscitation 2014; 16: 90 -95

118 Ernst S, Luther B, Zimmermann $N$ et al. Current diagnosis and therapy of non-occlusive mesenteric ischemia. Fortschr Röntgenstr 2003; 175: $515-523$

119 Rhee RY, Gloviczki P. Mesenteric venous thrombosis. Surg Clin North Am 1997; 77: 327-338

120 Boley SJ, Kaleya RN, Brandt LJ. Mesenteric venous thrombosis. Surg Clin North Am 1992; 72: 183-201

121 Bradbury MS, Kavanagh PV, Bechtold RE et al. Mesenteric venous thrombosis: diagnosis and noninvasive imaging. Radiographics 2002 22: $527-541$

122 Chou CK, Mak CW, Tzeng WS et al. CT of small bowel ischemia. Abdom Imaging 2004; 29: $18-22$

123 Wiesner W, Khurana B, Ji H et al. CT of acute bowel ischemia. Radiology 2003; 226: $635-650$

124 Lee SS, Ha HK, Park SH et al. Usefulness of computed tomography in differentiating transmural infarction from nontransmural ischemia of the small intestine in patients with acute mesenteric venous thrombosis. J Comput Assist Tomogr 2008; 32: 730 - 737

125 Kirkpatrick ID, Kroeker MA, Greenberg HM. Biphasic CT with mesenteric CT angiography in the evaluation of acute mesenteric ischemia: initial experience. Radiology 2003; 229: 91 -98

126 Wichman HJ, Cwikiel W, Keussen I. Interventional treatment of mesenteric venous occlusion. Polish journal of radiology 2014; 79: 233-238

127 Budjan J, Michaely HJ, Attenberger $U$ et al. Assessment of acute intestinal graft versus host disease by abdominal magnetic resonance imaging at 3 Tesla. Eur Radiol 2014; 24: 1835 - 1844

128 Schreyer AG, Landfried K, Jung EM et al. Contrast-enhanced ultrasound for differential diagnosis of suspected GvHD in patients after allogeneic transplantation. Clinical hemorheology and microcirculation 2011; 49: 129-136

129 Schreyer AG, Landfried K, Zorger $N$ et al. Transmural penetration of intravenously applied microbubbles during contrast-enhanced ultrasound as a new diagnostic feature in patients with GVHD of the bowel. Bone marrow transplantation 2011; 46: 1006 - 1011

130 Hoffstetter P, Schleder S, Jung EM et al. Konventionelle Abdomenübersichtsaufnahmen - welchen klinischen Nutzen hat die Aufnahme in Rückenlage? Deutsche medizinische Wochenschrift 2011; 136: $2589-2593$

131 Egger L, Fikentscher T, Poschenrieder F et al. Klinischer Stellenwert der Durchleuchtung der Magen-Darm-Passage (MDP) an einem Universitatsklinikum. Fortschr Röntgenstr 2012; 184: 893-898

132 Bulakci M, Kalelioglu T, Bulakci BB et al. Comparison of diagnostic value of multidetector computed tomography and X-ray in the detection of body packing. European journal of radiology 2013; 82: 1248 - 1254

133 Poletti PA, Canel L, Becker CD et al. Screening of illegal intracorporeal containers ("body packing"): is abdominal radiography sufficiently accurate? A comparative study with low-dose CT. Radiology 2012; 265: $772-779$ 